Provided for non-commercial research and education use. Not for reproduction, distribution or commercial use.

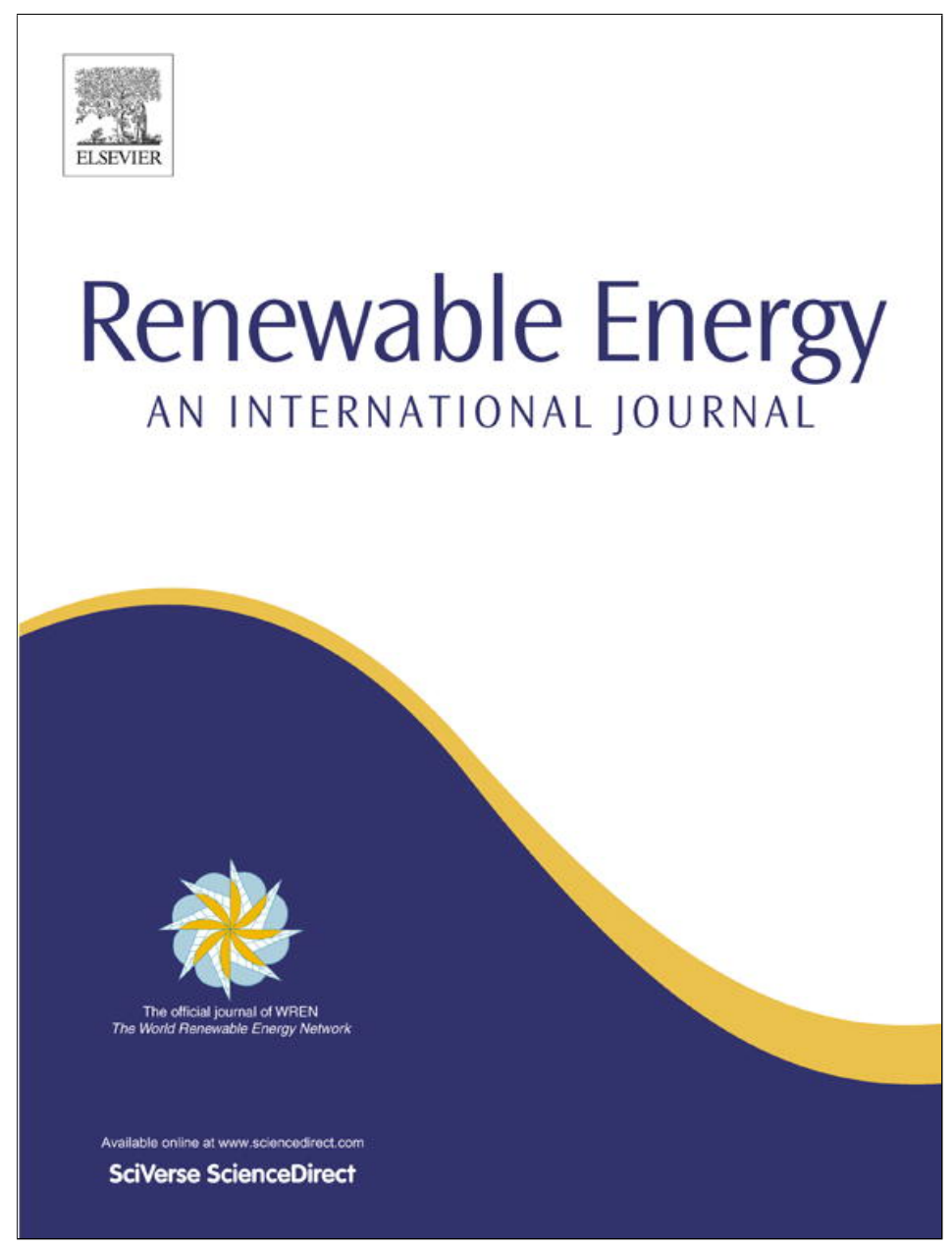

(This is a sample cover image for this issue. The actual cover is not yet available at this time.)

This article appeared in a journal published by Elsevier. The attached copy is furnished to the author for internal non-commercial research and education use, including for instruction at the authors institution and sharing with colleagues.

Other uses, including reproduction and distribution, or selling or licensing copies, or posting to personal, institutional or third party websites are prohibited.

In most cases authors are permitted to post their version of the article (e.g. in Word or Tex form) to their personal website or institutional repository. Authors requiring further information regarding Elsevier's archiving and manuscript policies are encouraged to visit:

http://www.elsevier.com/copyright 


\title{
Waste capiz (Amusium cristatum) shell as a new heterogeneous catalyst for biodiesel production
}

\author{
Wijaya Suryaputra, Indra Winata, Nani Indraswati, Suryadi Ismadji* \\ Department of Chemical Engineering, Widya Mandala Surabaya Catholic University, Jalan Kalijudan 37, Surabaya 60114, Indonesia
}

\section{A R T I C L E I N F O}

\section{Article history:}

Received 12 November 2011

Accepted 15 August 2012

Available online

\section{Keywords:}

Biodiesel

Transesterification

Catalyst

Capiz shell

Palm oil

\begin{abstract}
A B S T R A C T
The waste Capiz shell was utilized as raw material for catalyst production for biodiesel preparation. During calcination process, the calcium carbonate content in the waste capiz shell was converted to $\mathrm{CaO}$. This calcium oxide was used as catalyst for transesterification reaction between palm oil and methanol to produce biodiesel. The biodiesel preparation was conducted under the following conditions: the mole ration between methanol and palm oil was $8: 1$, stirring speed was $700 \mathrm{rpm}$, and reaction temperature was $60{ }^{\circ} \mathrm{C}$ for 4,5 , and $6 \mathrm{~h}$ reaction time. The amount of catalyst was varied at $1,2,3,4$, and $5 \mathrm{wt} \%$. The maximum yield of biodiesel was $93 \pm 2.2 \%$, obtained at $6 \mathrm{~h}$ of reaction time and $3 \mathrm{wt} \%$ of amount of catalyst. In order to examine the reusability of catalyst developed from waste of capiz (Amusium cristatum) shell, three transesterification reaction cycles were also performed.
\end{abstract}

() 2012 Elsevier Ltd. All rights reserved.

\section{Introduction}

Recently, alternative energy has been in the limelight because of energy crisis. Biodiesel is one of the most potential alternative energy since it is renewable and environmental friendly. Biodiesel is produced by transesterification of oils or fats (vegetable oils and animal fats) with alcohol to produce alkyl fatty acid esters and glycerol as a by-product. Currently, the studies of preparation of biodiesel using various kinds of oils and catalysts are very popular, and within few years thousands of research articles in this area have been published. In general there are three basic routes to biodiesel production from oils and fats: base catalyzed transesterification of the oil, direct esterification of the oil, and conversion of the oil to its fatty acids and then to biodiesel.

In industrial scale biodiesel production, the homogeneous alkali catalyst such as $\mathrm{NaOH}$ or $\mathrm{KOH}$ usually employed as catalyst due to faster reaction rate and required mild reaction condition [1]. However, the drawbacks of using homogeneous catalysts in biodiesel production are competing saponification reaction also occurs (if the amounts of FFA and water greater than $0.5 \%$ and $0.3 \%(w / w)$, respectively) and contamination of biodiesel product with catalyst [1]. Furthermore the regeneration of homogeneous catalysts after the transesterification process is very difficult and produces toxic wastewater [2].

\footnotetext{
* Corresponding author. Tel.: +62 313891264; fax: +62 313891267.

E-mail address: suryadiismadji@yahoo.com (S. Ismadji).
}

The search of alternative catalysts as substitutes for homogenous catalysts has been conducted for some years, and scientists found that heterogeneous catalysts offer several advantages than the homogeneous ones such as reusable, easy to separate, low sensitivity towards FFA and moisture content, more environmentally friendly, etc. Basically, the heterogeneous catalysts can be grouped into several types: alkali catalysts, acid catalyst, and enzymatic catalysts [3]. The heterogeneous alkali catalysts include

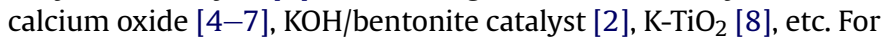
solid acid catalysts include sulphonic acid resin [9], acid modified organo-clay [10], $\mathrm{H}_{3} \mathrm{PW}_{12} \mathrm{O}_{40} / \mathrm{Ta}_{2} \mathrm{O}_{5}$ [11], zirconium sulfate supported on HMS-5 [12], aluminum hydrogen sulfate [13]. For enzymatic catalyst used in the biodiesel production is an intracellular lipase [14]. The main problem for utilization of these heterogeneous catalysts is in its price, most of these catalysts are expensive and complicated to prepare in large scale production, therefore limits their potential application in industrial scale operation.

Calcium oxide is one of the most promising heterogeneous alkali catalysts since it is cheap, abundantly available in nature (as limestone), and some of the sources of this compound are renewable (waste material consisting of $\mathrm{CaCO}_{3}$ ). Beside of the economic advantage, the performance of $\mathrm{CaO}$ as catalyst for biodiesel production also comparable to several homogeneous catalysts [15]. To the present, there are few studies concerning the utilization of waste materials as the resource of $\mathrm{CaO}$ for biodiesel production $[4,6,7,15,16]$. In this paper we utilized waste Capiz (Amusium cristatum) shell as the source of $\mathrm{CaO}$ for 
transesterification of palm oil into biodiesel. As an archipelago country, Capiz (A. cristatum) is found in several parts of Indonesia. Currently, the production of Capiz (A. cristatum) is quite large and the processing of this sea food also produces significant amounts of shell waste. Thus, the utilization of this waste material as a catalyst for biodiesel production is not only effective in reducing the cost of the biodiesel product but also related to recycle of the natural mineral resources [15]. Currently, to our best of knowledge, no one has reported the use of waste Capiz shell as a new resource of heterogeneous catalyst in biodiesel production.

\section{Materials and methods}

\subsection{Materials}

Waste Capiz (A. cristatum) shell was obtained from the local fish market in Surabaya, Indonesia. Raw Capiz shell waste was repeatedly washed with tap water to remove dirt and other unwanted materials. Subsequently, clean Capiz shell waste was dried in the oven at $100{ }^{\circ} \mathrm{C}$ for $24 \mathrm{~h}$. Then the shell was pulverized using JUNKE \& KUNKEL hammer mill. The Capiz shell powder was calcined in the furnace at $900{ }^{\circ} \mathrm{C}$ for $2 \mathrm{~h}$. The solid result was crushed and sieved to pass 170 mesh screens. The catalyst powder was kept in desiccators for further use.

Refined palm oil (Bimoli) obtained from local supermarket was used as the raw material for biodiesel preparation. Methanol was purchased as analytical grade from Sigma Aldrich. The standard reference for FAME analysis (methyl palmitate, methyl myristate, methyl oleate, methyl stearate, methyl laurate, and methyl linoleate) and methyl heptadecanoate were also obtained from Sigma Aldrich.

\subsection{Catalyst characterization}

The characterization of Capiz shell and the catalyst was conducted using Fourier Transform Infrared Spectroscopy (FTIR), X-Ray powder Diffraction (XRD), and X-Ray Fluorescence (XRF). The FTIR measurement was carried out by FTIR Spectrophotometer (Shimadzu 8400S) using the $\mathrm{KBr}$ technique with wavenumber range of $700-4000 \mathrm{~cm}^{-1}$. The XRD pattern of Capiz shell and catalyst were recorded on a Bruker DS Advance diffractometer at a wavelength $1.54056 \AA$, using $\mathrm{Cu} \mathrm{K} \alpha$ radiation measured from 5 to $90^{\circ}(2 \theta)$. While Rigaku ZSX100e X-Ray Fluorescence was used to determine the chemical composition of the catalyst.

\subsection{Transesterification of palm oil}

The transesterification of palm oil was conducted in a threeneck round bottom flask equipped with a reflux condenser, heating mantle controller, and mechanical stirrer. The transesterification procedure was carried out as follow: methanol and palm oil $(125 \mathrm{~mL})$ were mixed with at ratio $8: 1$. Then, the catalyst was added at certain ratio $(1 \%, 2 \%, 3 \%, 4 \%$, and $5 \%$ of palm oil weight). The mixture then was heated at $60{ }^{\circ} \mathrm{C}$ with continuous stirring at $700 \mathrm{rpm}$ until the completion of the reaction. The reaction time was kept at 4,5 , and $6 \mathrm{~h}$. The calcium oxide catalyst was recovered by centrifugation. The filtrate was kept in the funnel separator for $24 \mathrm{~h}$ until it separate into two layers. The top layer consisted of biodiesel, non-reacted palm oil, and small amount of excess methanol. The bottom layer composed of glycerol, excess methanol and other product from secondary reactions. After separation, the excess methanol was removed by evaporation at vacuum condition.

\subsection{Characterization of biodiesel yield}

The composition of FAME in the biodiesel produced by transesterification of palm oil and methanol using catalyst derived from Capiz shell waste was determined using gas chromatography (GC Shimadzu 2014). The GC was equipped with a DB-Wax capillary column (Agilent JW Scientific) and flame ionization detector (FID). The Helium was employed as the carrier gas at $40 \mathrm{~cm} / \mathrm{s}$. The injector temperature was $250{ }^{\circ} \mathrm{C}$ at splitless condition. The FID was set at $300{ }^{\circ} \mathrm{C}$. The initial oven temperature was $50{ }^{\circ} \mathrm{C}$ with an equilibration time of $3 \mathrm{~min}$. After isothermal period, the oven temperature was increased to $250^{\circ} \mathrm{C}$ at a heating rate of $10^{\circ} \mathrm{C} / \mathrm{min}$ and held for $8 \mathrm{~min}$. Peaks of methyl esters were identified by comparing them with the reference standard. The yield of biodiesel was determined by the following equation:

$$
\begin{aligned}
\text { Yield }(\%)= & (\text { product mass }) *(\text { FAME mass fraction }) *(100 \%) / \\
& \times(\text { palm oil mass })
\end{aligned}
$$

where 'product' refers to mixture of biodiesel (FAME) plus other compounds not identified as FAME (monoacylglycerols, diacylglycerols, etc.). Several physical properties of biodiesel produced in this study were also determined according to the ASTM standard and the results were compared with Indonesia National Standard for biodiesel. The kinematic viscosity was determined based on ASTM D445-10, 2010. The ASTM standard D.93, 2010 was used for determination of flash point, while the cetane index was analyzed according to ASTM D.613, 2010, and the determination of density or specific gravity of biodiesel based on ASTM D.1298, 2005.

\section{Results and discussion}

\subsection{Characterization of capiz shell and CaO catalyst}

The XRD patterns of Capiz shell and calcium oxide catalyst are given in Fig. 1. The Capiz shell consists mainly of calcium carbonate as indicated by diffraction peak at $2 \theta$ around 29.2. Peaks of calcium oxide along with some peaks of calcium hydroxide were observed when the shell was calcined at $900^{\circ} \mathrm{C}$ as indicated in Fig. 1. The XRF analysis result confirmed that the composition of calcined Capiz shell at $900{ }^{\circ} \mathrm{C}$ mainly consists of $\mathrm{CaO}$ (96.15\%). The X-ray fluorescence (XRF) pattern of catalyst $\mathrm{CaO}$ is depicted in Fig. 2.

FTIR spectra of Capiz shell and calcined Capiz shell are shown in Fig. 3. Two well defined infrared bands around 868 and $1420 \mathrm{~cm}^{-1}$ are characteristic of the $\mathrm{C}-\mathrm{O}$ stretching and bending modes of $\mathrm{CaCO}_{3}$ [17]. The intensity of these bands decreases and alter during calcinations at $900{ }^{\circ} \mathrm{C}$ due to thermal decomposition of $\mathrm{CaCO} 3$ and formation of $\mathrm{CaO}$ and $\mathrm{Ca}(\mathrm{OH})_{2}$. One sharp band appears $3620 \mathrm{~cm}^{-1}$ due to the formation of basic $\mathrm{OH}$ groups attached to the calcium atoms [17]. The new band of $\mathrm{OH}$ groups was due to the abstraction of protons from the acidic molecular probe on the surface oxygen anion [15]. Further explanation about the mechanism of $\mathrm{OH}$ groups formation can be seen in the review paper by Kouzu and Hidaka [15]. These evidences are in line with the XRD results given in Fig. 1.

\subsection{Transesterification of palm oil with methanol into biodiesel}

Transesterification reaction is a series of consecutive reactions in which esters and glycerol are produced [18]. The yield of biodiesel obtained at various catalyst ratios and reaction time is summarized in Table 1. From this table it can be seen that the yield of biodiesel increase with increase of the catalyst amount to $3 \%$, further increase of catalyst reduce the biodiesel yield. As a catalyst, 
a

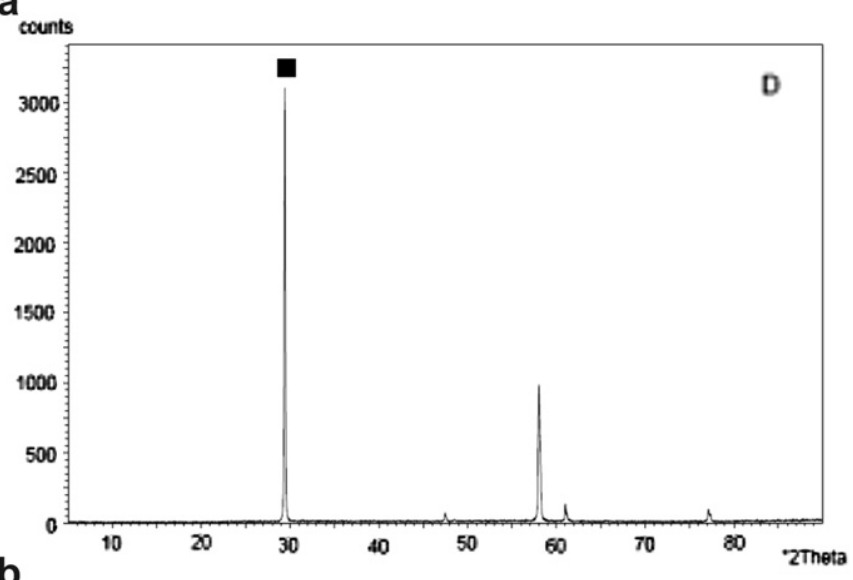

b

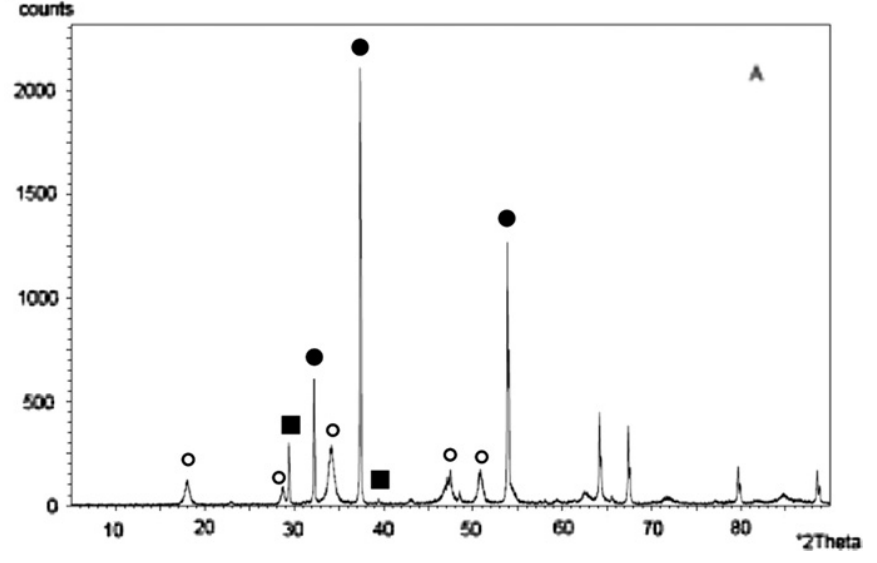

Fig. 1. XRD patterns for (a) capiz shell and (b) calcined capiz shell ( $\mathbf{\square}), \mathrm{CaCO}$; $\mathrm{CaO} ;(\mathrm{O}), \mathrm{Ca}(\mathrm{OH})_{2}$. the catalytic role of $\mathrm{CaO}$ is to abstract proton from organic matter of the basic sites generated on the surface of solid, and this proton initiates the base catalyzed reaction [15]. For transesterification of palm oil with methanol, in the initial stage, the catalytic role of the basic site of $\mathrm{CaO}$ is to abstract proton from methanol and allow methanol to be transformed into nucleophile (calcium methoxide) which subsequent attacks carbonyl carbon in a molecule of triglyceride $[15,19]$. After the reaction occurred and appreciable amounts of glycerol were produced, available $\mathrm{CaO}$ reacted with glycerol under transesterification conditions to form calcium glyceroxide $[20,21]$. The later is less active than calcium methoxide in transesterification of vegetable oil into biodiesel. Calcium glyceroxide reacted further with the excess methanol under transesterification condition [20] to form $\mathrm{CH}_{3} \mathrm{O}-\mathrm{Ca}-\mathrm{O}(\mathrm{OH})_{2} \mathrm{C}_{3} \mathrm{H}_{5}$, which also has lower basic strength than $\mathrm{CaO}$. With the increase of $\mathrm{CaO}$ above $3 \%$, the amount of $\mathrm{CaO}$ was in excess, and the formation of calcium glyceroxide also increases leading to increase the amount of $\mathrm{CH}_{3} \mathrm{O}-\mathrm{Ca}-\mathrm{O}(\mathrm{OH})_{2} \mathrm{C}_{3} \mathrm{H}_{5}$. Since the later form of $\mathrm{Ca}$ was less active therefore the conversion of reaction decrease and less amount of biodiesel produced.

The reaction time has a positive effect on the yield of biodiesel as seen in Table 1. Increasing reaction time also increases the biodiesel yield, since the contact time between reactants increase, however, further increase of reaction time gave no significant effect on the yield of biodiesel since the equilibrium condition almost reached. The effect of different process variable on the yield of biodiesel is also given in 3D graph as seen in Fig. 4.

One of the objectives of using heterogeneous catalyst for biodiesel production is reusability and stability of the catalyst. In order to examine the reusability of catalyst developed from waste of capiz (A. cristatum) shell, three transesterification reaction cycles were performed. The reaction cycles were performed at the following operation condition: the molar ratio of oil to methanol $1: 8$, the amount of catalyst $3 \%$, reaction time $1-5 \mathrm{~h}$, reaction temperature $60{ }^{\circ} \mathrm{C}$. For fresh catalyst, the maximum yield of biodiesel was 92.83. After the separation from liquid mixtures, the $\mathrm{CaO}$ catalyst was repeatedly washed with methanol and re-calcined at $900{ }^{\circ} \mathrm{C}$

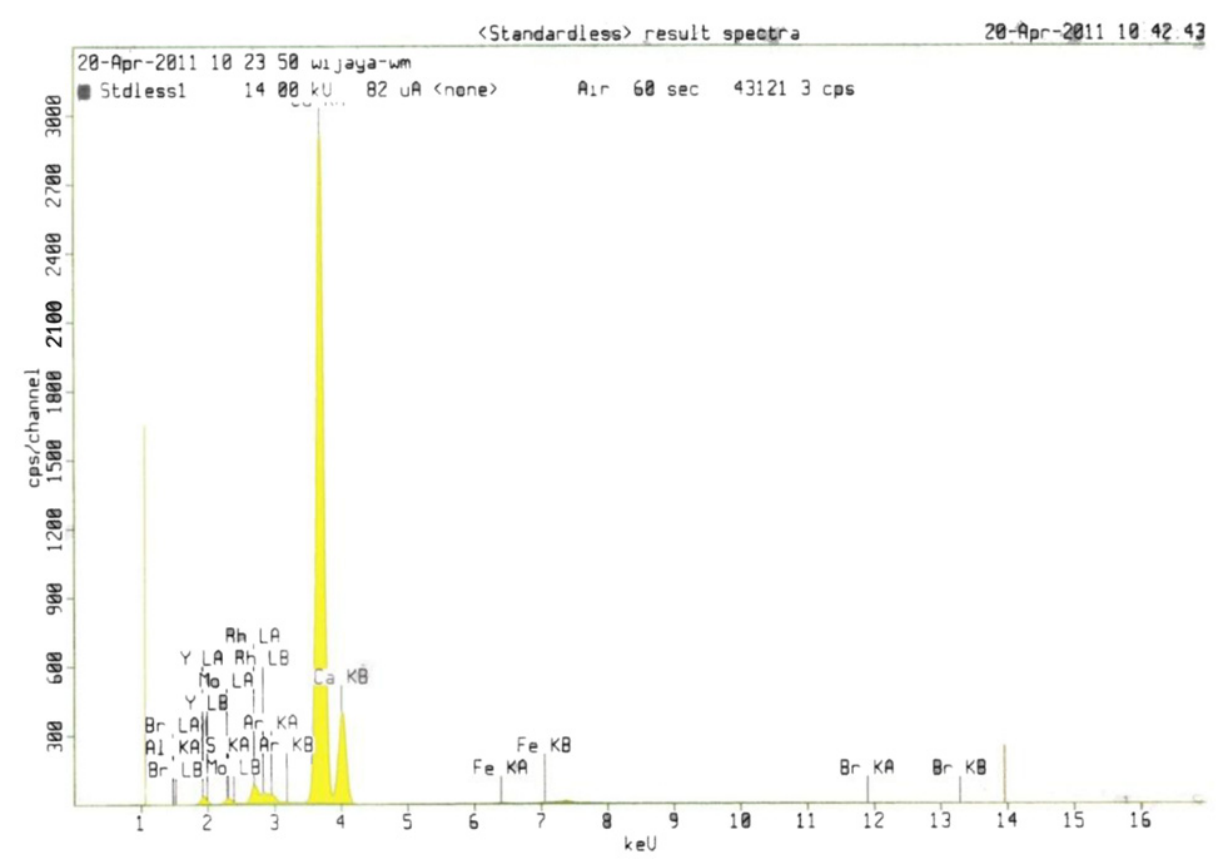

Fig. 2. The XRF spectra for calcined capiz shell (catalyst). 


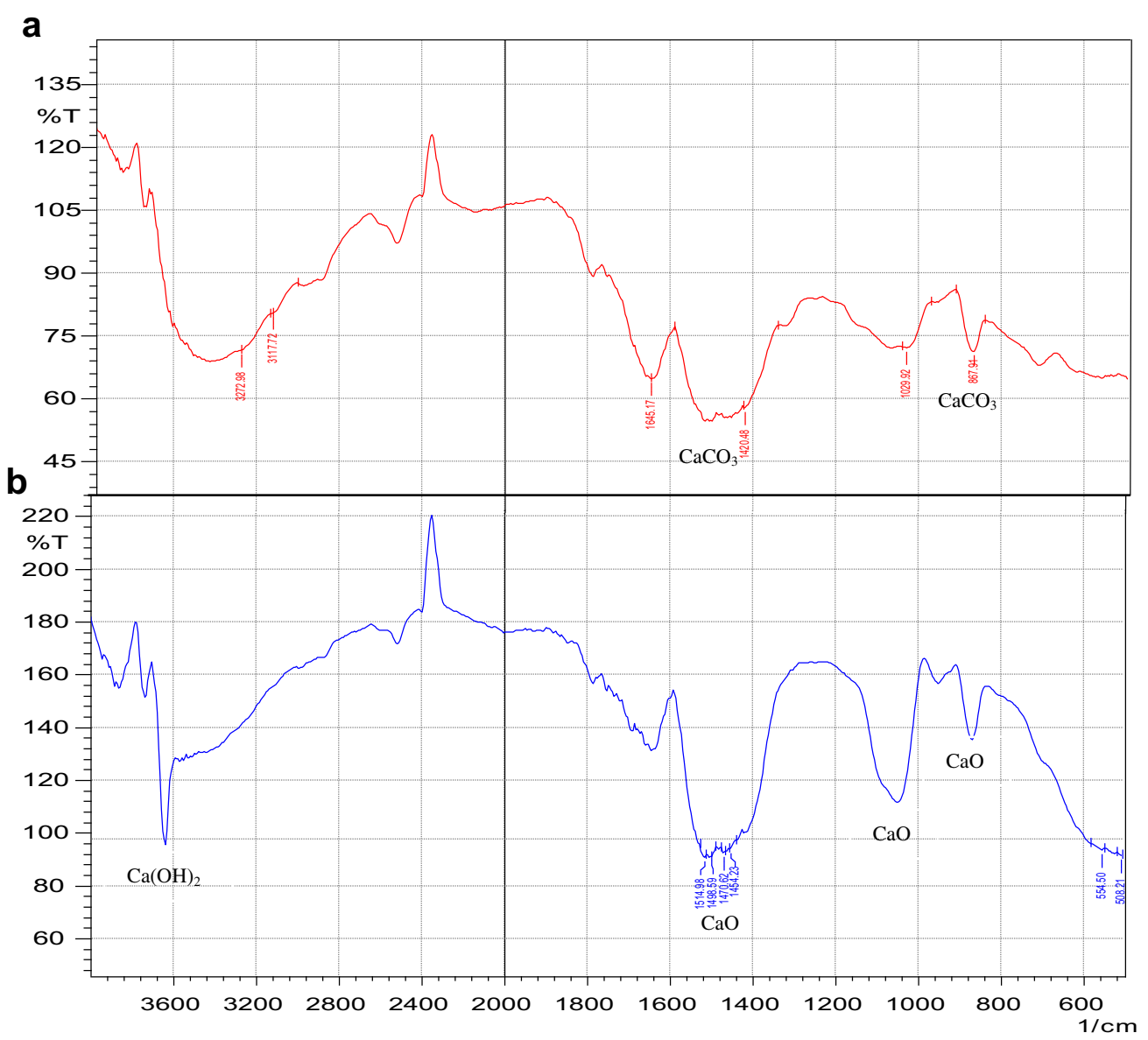

Fig. 3. FTIR patterns of (a) capiz shell, and (b) calcined capiz shell (catalyst).

for $2 \mathrm{~h}$. Subsequent cycles was started with fresh reactants. The experimental cycles test results are depicted in Fig. 5. The results clearly shown that the yield decreased with the repeated used of waste Capiz shell derived catalysts. For the third cycle, the catalytic activity decreases almost $50 \%$ from fresh catalyst.

As mentioned by Kouzu and Hidaka [15] that the de-activation of $\mathrm{CaO}$ catalyst usually caused by several factors such as the contact of basic sites of catalyst with ambient $\mathrm{CO}_{2}$ and $\mathrm{H}_{2} \mathrm{O}$, neutralization of basic sites with free fatty acid, and leaching of $\mathrm{CaO}$ catalyst onto polar solvent such as methanol. In our preliminary experiments we also have studied the effect of exposing our

Table 1

The effect of different process variable on the yield of biodiesel.

\begin{tabular}{lll}
\hline Reaction time, $\mathrm{h}$ & Amount of catalyst, \% & Yield of biodiesel, \% \\
\hline 4 & 1 & $83 \pm 2.7$ \\
4 & 2 & $85 \pm 3.0$ \\
4 & 3 & $90 \pm 1.8$ \\
4 & 4 & $74 \pm 3.2$ \\
4 & 5 & $70 \pm 2.4$ \\
5 & 1 & $89 \pm 2.9$ \\
5 & 2 & $93 \pm 2.2$ \\
5 & 3 & $93 \pm 2.0$ \\
5 & 4 & $81 \pm 3.1$ \\
5 & 5 & $79 \pm 1.3$ \\
6 & 1 & $89 \pm 2.9$ \\
6 & 2 & $93 \pm 2.5$ \\
6 & 3 & $93 \pm 2.2$ \\
6 & 4 & $84 \pm 2.9$ \\
6 & 5 & $81 \pm 3.3$ \\
\hline
\end{tabular}

catalyst in ambient atmosphere on its catalytic activity, and less than 30 min the catalytic activity was reduced almost $20 \%$ comparing to catalyst store in desiccators under vacuum condition. Similar result was also observed by Kouzu et al. [21]. The FFA content also plays significant role in the deactivation of $\mathrm{CaO}$ catalyst derived from waste Capiz (A. cristatum) shell. In the beginning of

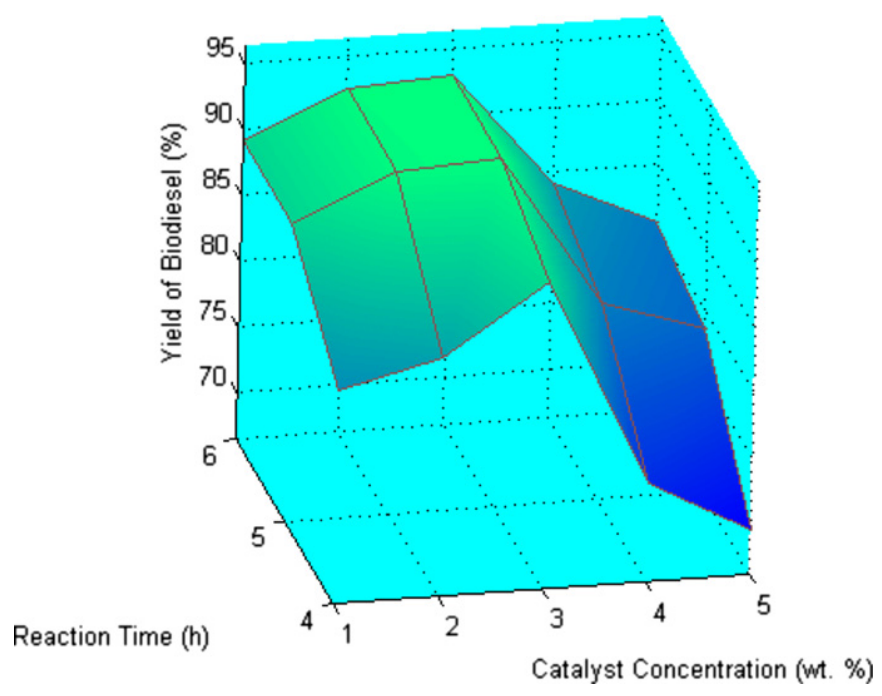

Fig. 4. The effect of reaction time and catalyst concentration on the yield of biodiesel. 


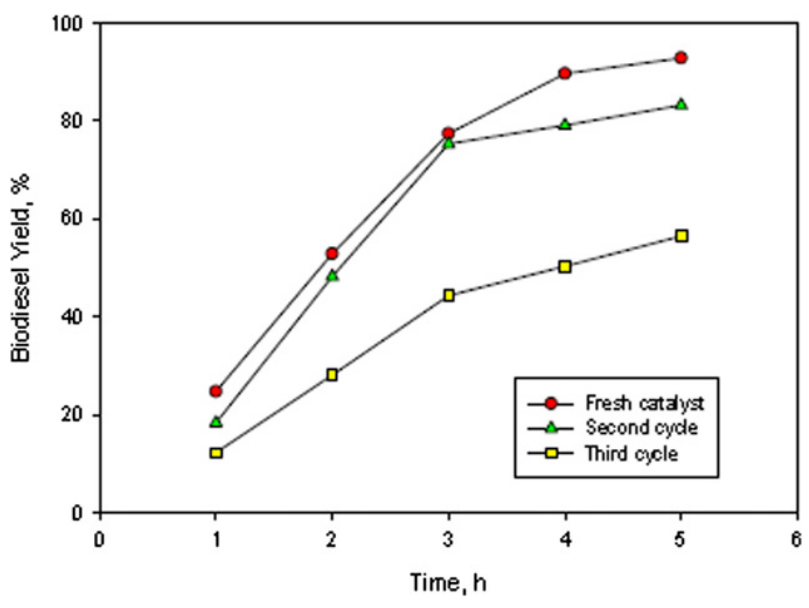

Fig. 5. Multiple test of $\mathrm{CaO}$ deactivation.

our study, in order to achieve economically reasonable biodiesel production, we employed low quality of palm oil. After the reaction completed, a turbid mixture was observed. Here the neutralization of $\mathrm{CaO}$ with FFA occurred and yielded calcium-carboxylate soluble in the liquid phase consisting of the oil emulsified with methanol. Similar results were found by many researchers as mentioned by Kouzu and Hidaka in their review paper [15].

The comparison of the physical characteristics of biodiesel produced from the transesterification of palm oil with methanol using waste capiz shell derived catalyst with those from Indonesia National Standard (SNI-04-7182-2006) are given in Table 2. The cetane index is the measurement of the combustion quality of diesel fuel during compression ignition. The cetane index has significant effects on engine performance such as combustion and exhaust emission. The biodiesel fuel with low cetane index makes the engine difficult to start and also produces noise and smoke exhaust gas $[2,22]$. The cetane index of biodiesel produced in this experiment according to ASTM D.613, 2010 is $55.1 \pm 0.2$, higher than Indonesia National Standard $(>45)$. Since the major contents of the biodiesel produced in this experiment are methyl palmitate and methyl oleate which are have the cetane index 59.3 and 85.9 [22], respectively. So the minimum requirement of standard biodiesel will easily fulfilled if the raw material for biodiesel production is palm oil.

The kinematic viscosity plays important role on the performance of injector and fuel atomization. If the viscosity is too low, the fuel may not provide sufficient lubricant for the fuel injection pump, however if the viscosity of fuel is too high or too viscous the problem is in the injection, it will produce larger droplets which can cause poor combustion [2]. The kinematic viscosity of biodiesel produced in this experiment $(5.22 \pm 0.14)$ was in the range of Indonesia National Standard of biodiesel. Flash point also one of the important characteristic of fuel since it relates to the ignition of the fuel. In order to handle the fuel properly and safely, a minimum value of flash point is required. Since the flash point of biodiesel

Table 2

Comparison of the properties of biodiesel produced by catalyst from waste capiz shell with the standard issued by Indonesia National Standard (SNI-04-7182-2006).

\begin{tabular}{lcl}
\hline Properties & Biodiesel produces & SNI \\
\hline Kinematic viscosity at $40{ }^{\circ} \mathrm{C}(\mathrm{cSt})$ & $5.2 \pm 0.1$ & $1.9-6.0$ \\
Cetane index & $55.1 \pm 0.2$ & $>45$ \\
Specific gravity $\left(15{ }^{\circ} \mathrm{C}\right)$ & $0.87 \pm 0.01$ & $0.86-0.90$ \\
Flash point $\left({ }^{\circ} \mathrm{C}\right)$ & $139.5 \pm 1.4$ & Min 65 \\
\hline
\end{tabular}

produced in this study $\left(139.5 \pm 1.4^{\circ} \mathrm{C}\right)$ was higher than Indonesia National Standard $\left(\min 65{ }^{\circ} \mathrm{C}\right)$, this fuel is safe for handling and storage for some period of time. Therefore the biodiesel produced from palm oil using catalyst from waste Capiz (A. cristatum) shell can be utilized as substitute fuel for diesel engines.

\section{Conclusion}

Waste Capiz (A. cristatum) shell has potential application as a renewable resource of catalyst for biodiesel production. The catalyst was obtained by calcinations of waste Capiz shell at $900{ }^{\circ} \mathrm{C}$ for $2 \mathrm{~h}$. The maximum yield of biodiesel produced by transesterification of palm oil with methanol was $93 \pm 2.2 \%$. The operating condition to achieve the maximum biodiesel yield is: the ratio of oil to methanol 1:8, the amount of catalyst $3 \%$, reaction time $6 \mathrm{~h}$, reaction temperature $60^{\circ} \mathrm{C}$.

\section{References}

[1] Kaur M, Ali A. Litium ion impregnated calcium oxide as nano catalyst for the biodiesel production from karanja and jatropha oils. Renew Energy 2011;36: 2866-71.

[2] Soetaredjo FE, Ayucitra A, Ismadji S, Maukar AL. KOH/bentonite catalysts for transesterification of palm oil to biodiesel. Appl Clay Sci 2011;53:341-6.

[3] Endalew AK, Kiros Y, Zanzi R. Inorganic heterogeneous catalysts for biodiesel production from vegetable oils. Biomass Bioenergy 2011;35:3787-809.

[4] Boro J, Thakur AJ, Deka D. Solid oxide derived from waste shells of Turbonilla striatula as a renewable catalyst for biodiesel production. Fuel Process Technol 2011;92:2061-7.

[5] Zabeti M, Daud WMAW, Aroua MK. Biodieel production using aluminasupported calcium oxide: an optimization study. Fuel Process Technol 2010; 91:243-8.

[6] Boey PL, Maniam GP, Hamid SA. Biodiesel production via transesterification of palm olein using waste mud crab (Scylla serrata) shell as a heterogeneous catalyst. Bioresour Technol 2009;100:6362-8.

[7] Viriya-empikul N, Krasae P, Puttasawat B, Yoosuk B, Chollacoop N, Faungnawakij K. Waste shells of mollusk and egg as biodiesel production catalysts. Bioresour Technol 2010;101:3765-7.

[8] Salinas D, Guerrero S, Araya P. Transesterification of canola oil on potassiumsupported $\mathrm{TiO}_{2}$ catalysts. Catal Commun 2010;11:773-7.

[9] Tesser R, Casale L, Verde D, Di Serio M, Santacesaria E. Kinetics of free fatty acids esterification: batch and loop reactor modeling. Chem Eng J 2009;154: 25-33.

[10] Ghiaci M, Aghabarari B, Gil A. Production of biodiesel by esterification of natural fatty acids over modified organoclay catalysts. Fuel 2011;90:3382-9.

[11] Xu L, Yang X, Yu X, Guo Y. Preparation of mesoporous polyoxometalatetantalum pentoxide composite catalyst for efficient esterification of fatty acid. Catal Commun 2008;9:1607-11.

[12] Juan JC, Zhang J, Yarmo MA. Study of catalyst comprising zirconium sulfate supported on a mesoporous molecular sieve HMS for esterification of fatty acids under solvent-free condition. Appl Catal A Gen 2008;347:133-41.

[13] Ramachandran K, Sivakumar P, Suganya T, Renganathan S. Production of biodiesel from mixed waste vegetable oil using an aluminum hydrogen sulphate as a heterogeneous acid catalyst. Bioresour Technol 2011;102: 7289-93.

[14] Gog A, Roman M, Tosa M, Paizs C, Irimie FD. Biodiesel production using enzymatic transesterification - current state and perspectives. Renew Energy 2012;39:10-6.

[15] Kouzu M, Hidaka J. Transesterification of vegetable oil into biodiesel catalyzed by $\mathrm{CaO}$ : a review. Fuel 2012;93:1-12.

[16] Hu S, Wang Y, Han H. Utilization of waste freshwater mussel shell as an economic catalyst for biodiesel production. Biomass Bioenergy 2011;35: 3627-35.

[17] Garcia J, Lopez T, Alvarez M, Aguilar DH, Quintana P. Spectroscopic, structural and textural properties of $\mathrm{CaO}$ and $\mathrm{CaO}-\mathrm{SiO}_{2}$ materials synthesized by sol-gel with different acid catalysts. J Non-Crystal Solids 2008;354:729-32.

[18] Marchetti JM, Errazu AF. Biodiesel production from acid oils and ethanol using a solid basic resin as catalyst. Biomass Bioenergy 2010;34:272-7.

[19] Hattori H, Shima M, Kabashima H. Alcoholysis of ester and epoxide catalyzed by solid bases. Stud Surf Sci Catal 2000;130:3507-10.

[20] Kouzu M, Hidaka J, Wakabayashi K, Tsunomori M. Solid base catalysis of calcium glyceroxide for a reaction to convert vegetable oil into its methyl esters. Appl Catal A Gen 2010;390:11-8.

[21] Kouzu M, Kasuno T, Tajika M, Yamanaka S, Hidaka J. Active phase of calcium oxide used as solid base catalyst for transesterification of soybean oil with refluxing methanol. Appl Catal A Gen 2008;334:357-65.

[22] Rashid U, Anwar F, Knothe G. Biodiesel from Milo (Thespesia populnea L.) seed oil. Biomass Bioenergy 2011;35:4034-9. 